\title{
Analysis of Online Audience Comment on 2016 Subsidy Removal Issue in Nigeria: A Case Study of Premium Times and Sahara Reporters
}

Umar MA*

Department of Mass Communication, University of Maiduguri, Nigeria

\begin{abstract}
The study analysed online audience comments on the 2016 subsidy removal issue in Nigeria. The analyses of the comments were made to find out the positive comments, negative comments, tones of comments (ethnic, regional, political) and the overriding position. The researcher employed the propositions and guidelines of Critical discourse analysis (CDA) and discursive psychology to analyse the comments, this is because it has suitable proposition that match the desire of the study. The study found that, negative comments had the highest portion of all the comment analysed while positive comments had smaller portion though it has significant number. The analysis found that among the negative comments, even the media that reported the issue was attacked. It was also found that some comments were fragmented in ethnic, political and regional tones. The study recommends that more online vetting of comment should be used by online media to ensure the positive exploitation and use of the platforms by the audience. The study further studies should be conducted to find out the diverse understanding, acceptance and rejection of government policies by Nigerian populace on the online platforms.
\end{abstract}

Keywords: Communication; Television; Digital; Technology

\section{Introduction}

In any communication chain, the audience is the element at which messages are targeted. Hermida [1] has referred audiences as "communicatee" which means the message recipients. Media collect, produce and transmit their messages to their target audiences. However, the nature of the media determines the nature of its audience. For instance Radio Medium has listeners as audience, television has viewers as audience and online Media has web users as its target audience.

According to Gurevitch et al. [2] due to digital technologies, audiences are becoming more and more active participants in public communication, in a way that media practitioners can no longer expect to operate within an exclusive professionalized enclave. In other words, with advancement in communication technology which has made it possible for the establishment of web-based media, audience participation has grown to a level that media practitioners cannot operate exclusively without audience involvement in their discourse. Even though, the audience participation is not a new phenomenon but the rise in mode of participation enabled by the new media has provided a leap forward in audience involvement in public communication.

Among the many types of audience participation generated by the interaction of Internet into media, audiences' comments in news are the most widely used in online news sites and common forms of citizen engagement online, with great potential for public discourse concern $[3,4]$. This platform has given the public a medium for expressing their perspectives on current issues and on matters of public [5]. The consumptions of media contents nowadays are not only restricted to reading, watching and browsing, but has developed to include contributing to media discourse. This feature spurred by the new media is a global phenomenon.

Nigeria being most populous nation in Africa has the highest number of web users African Telecommunication Research Report (ATRR). According to Wilson and Gapsiso [6] Nigerians are passionate about expressing their minds on issues of national importance. They identified that these expression cut across all sphere of national endeavours such as politics, religion, family, economy, culture, corruption, government policies, sports etc. and media serving as channel. Research has established that the availability of interactive features in news sites distinguishes online journalism from its offline counterparts. Interactivity signifies a shift from the traditional media one-to-many communication flow to the emergence of a two-way communication model which converts online audiences from passive to active media consumers.

The potential of interactivity to facilitate a dialogue between the media and its audiences is therefore in-disputable. The users' comments (audience comment) have only recently been broadly adopted by news sites and thus they have yet to receive much attention in the literature. Audience comments can be understood as civic forums, where citizens contribute their views, exchange and ideas. Thus, user comments are an interesting subject for investigation in the context of audience participation in journalism.

In this light, readers' comments can be seen as a desirable contribution to journalism and a healthy democratization of discourse. Research has not only shown that online news comments are a dynamic space for exchange of ideas and arguments exchange but journalists themselves recognize their potentials to fulfill deliberative ideals when engaging their audience in the discussion of public issues [3].

Groups and individuals have often exploited the audience comment platform to mobilize citizens. For example Wilson and Gapsiso [6] pointed out that group like Occupy Nigeria, was a socio-political protest movement that began in Nigeria on Monday, 2 January 2012 in response to the fuel subsidy removal by the Federal government. The media coverage of the issue showed how much concern it has

${ }^{*}$ Corresponding author: Umar MA, Department of Mass Communication, University of Maiduguri, Nigeria, Tel: 08136464011; E-mail: muhammadauwal32@gmail.com

Received December 04, 2017; Accepted March 16, 2018; Published March 20, 2018

Citation: Umar MA (2018) Analysis of Online Audience Comment on 2016 Subsidy Removal Issue in Nigeria: A Case Study of Premium Times and Sahara Reporters. J Mass Communicat Journalism 8: 363. doi: 10.4172/2165-7912.1000363

Copyright: (๑) 2018 Umar MA. This is an open-access article distributed under the terms of the Creative Commons Attribution License, which permits unrestricted use, distribution, and reproduction in any medium, provided the original author and source are credited. 
generated. In 2012 during President Jonathan's Administration, before the subsidy removal (PMS) petrol was sold for N65 per litre but as soon as the announcement was made, it rose to N97 official price. Though, the subsidy removal was partial it affected the lives of citizens everywhere thus, triggering public response via online platforms [7].

Under the present administration of President Muhammadu Buhari, the Federal Government on $11^{\text {th }}$ May, 2016 announced the total removal of the subsidy on downstream oil sector. The Minister of State for Petroleum Resources, Ibe Kachikwu announced the removal on the background of the fuel scarcity and supply difficulties in the country which generated several comments in the various online platforms including the online news media.

This study analyses audience comments on subsidy removal issue in Nigeria in 2016 in online sites of two prominent online media: Sahara Reporters and Premium Times.

\section{Statement of the Problem}

The advent of online news media has given freedom to online audience to respond and comment on various issues without hindrance. Various Studies have been conducted on online users' comments over national and international issues $[8,9]$. These studies analysed issues in respect of audience comments on various national issues. However, there hasn't been a documented study on the comments of Nigerians on the total deregulation of the downstream oil sector by Buhari led government in 2016. Therefore, this study fills a gap in knowledge by analysing audience comment on 2016 fuel subsidy removal in Nigeria.

\section{Objectives of the study}

To find out the online audience positive and negative comments on the subsidy removal issue in Nigeria in 2016.

To examine how the tones of the comments on subsidy removal in Nigeria in 2016 are segmented.

To examine the overriding position (between positive or negative) of the online audience comments on subsidy removal in Nigeria in 2016.

\section{Research questions}

Are there positive online audience comments on the subsidy removal issue in Nigeria in 2016?

Are there negative online audience comments on the subsidy removal issue in Nigeria in 2016?

What are the tones (political, regional and ethnic) of the comments on the subsidy removal issue in 2016 segmented?

What is the overriding acceptance or rejection of 2016 subsidy removal in Nigeria in the online audience comments?

\section{Operational definitions}

Audience: In the context of this study, Audience is the element in a communication chain which refers to message recipient. The receiver of a message is the target audience of media organizations.

Online audience: With regard to this study, the concept of Online Audience refers to anybody who read news reports, features, and watches and download movies among other means of consumption.

Online media: For the purpose of this research the online media is well established media organization which based its operation on the internet platforms. It operates either on websites, blogs, vlogs, mini sites and other online platforms.

Subsidy removal: Subsidy is the money paid by a government with the aim of reducing the cost and supply difficulty of a particular product or service to people of a country. Subsidy is paid to support the market of a particular good so that citizens will enjoy cheaper purchase.

Audience comments: In the context of this study, the users' comments refers to the ability of readers to express their opinions on news reports, opinion pieces, journalists' blogs, and any other content available on the site. In essence everyone with an Internet access can 'talk back' to media and to each other on high-profile issues. Audiences' comments can be understood as civic forums, where citizens contribute their views, exchange ideas and where civic talk can take place.

\section{Literature Review}

In media studies, audience are people, either as groups or as individuals. It also refers to large groups of people, like the mass audience for television news, newspaper readerships, people in the cinema or even people attending a major sporting event or a rock concert. The people in such groups are seen as having connection with each other in terms of the interest in the event they are attending or witnessing. The audience comment or sometimes referred as "users' comments feature" refers to the ability of readers to express their opinions on news reports, opinion pieces, journalists' blogs and any other content available on the site. In essence everyone with an Internet access can 'talk back' to reporters and to each other on high-profile issues. According to Hille and Bakker "User Comments" are interesting subjects for investigation in the context of audience participation in journalism.

Audience participation in news websites comes in various shapes and forms, e.g., Just as user involvement in the use and creation of the content of interactive media can be graduated into different degrees [10], Wahl-Jorgensen et al. [11] focusing on the field of news and journalism, distinguish between "audience comment" and "audience content"; that is, between audience contributions based on, respectively, opinions and facts. These researchers also established how producers and audience appreciate substantial, fact-based audience participation while they discard opinionated contributions.

Audience participation is primarily possible in the shape of audience comments and similar interpretational categories where ordinary people react to the news that has already been produced $[1,12]$. At the same time, they are one of most common forms of citizen engagement online, with great potential for public discourse giving the public a medium for expressing their perspectives on current issues and on matters of public concern $[4,5]$. Audience participation is growing and evolving as a new tool of brand activation and brand engagement [13].

There are however different types of participation in media discourse and even production [13]. These are; Information participation, Collaboration participation, Conversation participation and Meta-communication Information: According to both Harrison and Hermida, this type of audience participation is one among the most commonly used on news websites, probably because it simultaneously draws upon the resources of the audience and allows the journalists to retain control over the news production.

\section{Collaboration}

Through this kind of participation, audience who happen to be in the right place at the right time transcend their role as eye witnesses and 
become some kind of amateur journalists who participate in blurring the distinction between audience and journalists.

\section{Conversation}

The third type of audience participation is conversation of a more sociable nature. Sociability is a prominent characteristic of a large proportion of the conversations that take place on digital media.

\section{Meta-communication}

The fourth type of audience participation is meta-communication; that is, about the very communication which the news constituted. Jensen (2010:94) describes meta-communication as the communication that takes place "above and beyond the exchange of literal information". That is what goes on here: through exchanges about the very coverage, the premises and processes behind the news production are made visible, so that audience can both follow the covered event and gain insight into a level 'above and beyond' the coverage of the event.

However, Vujnovic [14] outlined that in respect to economic considerations within news outlets, readers' comments may bring concrete benefits such as brand-building, user-loyalty and boosting website traffic thus; possibly attracting advertisers. In online media, at the end of news articles, readers want to express personal opinions, interact with one another, act as entertainers, or express intense emotional reaction [15].

Nonetheless, a series of studies had demonstrated that the use of interactive features by mainstream news sites is relatively limited, especially features that promote user-to-user interactions. Consequently, research by Reich [3] have indicated that readers' comments might pose several challenges to journalists and newsrooms, due to an array of aspects: quality concerns related to the presence of inappropriate speech, such as hate speech, racism, defamation, abusive comment, incivility, or linguistic. Thus, some newsrooms are deciding to move online comments from their websites to Facebook commenting.

Singer and Ashman assert that the anonymity of the online users, mainly understood as a factor in the uncivil tone of online discourse which may affect a news organization's reputation. This factor emanates from the 'free world' nature of the online platforms. Even though audience participation in news production is not a new phenomenon, it is a far more prominent feature online than in traditional news media. With digital, interactive media, the flow of communication has moved beyond the classic transition model of content passing only from senders to receivers to a two way communication between audience and the media.

The digital media have enabled multi-directional communication flows where "the people formerly known as the audience" [16] have increased opportunities to more directly influence and participate in the production of media content. The implication is that the common understanding of news as something produced by actors with a certain professional background within certain institutions and organizations has changed, as news production now also takes place beyond the news organizations. Bruns has introduced the relevant concept of the produser, which amalgamates 'producer' and 'user' and captures how the role of the audience now also comprises a potential element of creation.

\section{Attributes of Online Audience}

As central focus of this study, the researcher choose category of online audience to shed more light on their attributes which in one way or the other differentiate them with the conventional audience. These attributes affect their relationships with the media and other audience as well. Some of the attributes are also applied to the conventional audience but are more complex and advance with online audience.

\section{Interactivity}

The ability to post comments on new sites is one of the greatest attributes of online audience which not only facilitates a communication between users (user-to-user interactivity) but it also enables users to create their own content (user-to-document interactivity). Interactivity signifies a shift from the traditional media one-to-many communication to the emergence of a two-way communication model which converts online audience from passive to active media consumers. The potential of interactivity to facilitate a dialogue between the media and its audiences is therefore indisputable.

Nonetheless, a series of studies has demonstrated that the use of interactive features by mainstream news sites is relatively limited, especially features that promote user-to-user interactions. The implication here is that online audience enjoys most privilege to interact with the media and even other audience.

\section{Anonymity}

Another element worth noting is the level of anonymity of the online audience while commenting or any other interaction with the media through the internet. The concept of anonymity here means the amount of information users are asked to provide before posting a comment. The information they provide does not serve enough templates to identify someone or even where they are commenting from, this is because there is a wide room for the audience to provide false information. In some instances, the information might be right but not reliable to identify the audience.

\section{Diversity}

Online audience are now considered to be more diverse than any other media be it radio, television, film or newspaper. Taking this attribute from the angle of Marshall McLuhan who predicted that the world will be a "Global Village" which has since been confirmed through the internet, people from all angles of the world, irrespective of their tribe, believe, age, religion, class, perspective, notion and culture come together to make up what is now called "Global Audience". Such combination of people attends to similar messages at their various leisure times. This puts online media into crucial situation to produce and deal with its audience. Unlike the traditional media, where notion of regionalism, sectionalism, nationalism and religious are common, dealing with online audience such (isms) must be balanced or totally avoided to fit and cover the audience.

\section{Freedom}

The widespread adoption of online media has empowered individuals to develop new forms of expression, reach new audience and quickly disseminate information around the world. From emails and blogs, to YouTube and Twitter, new digital technologies are enabling people who otherwise might not have been heard to express themselves and engage in far-flung conversations that were once near impossible. However, threats to free expression are just as prevalent online as they are off. Internet use and social media in particular, has allowed for the disruption of the power dynamics of global communications.

The change in the flow of information has altered traditional 
mechanisms of institutional control. Although there are clearly exceptions, major traditional (or offline) media outlets are typically concentrated in the hands of a few - mainly large corporations. Traditional media such as television or newspapers can be quite expensive, and require specific skills and expertise to produce. Online media have disrupted this structure, by enabling almost anyone who wants to publish or broadcast their views to become a content producer. Audience sizes have also grown online, as a single Twitter feed or small online news platform can now potentially reach far more people than traditional media ever could. To help keep up, traditional media outlets are now integrating with online media, which has resulted in the added benefit of their content also becoming more widely accessible.

\section{Online based (internet based)}

There is quite a presence on the Internet. Through the Internet, every person is given the opportunity to participate in different ways. The Internet gives people a platform to write and reach the people who are interested in what they are writing about. When writers write online, they are able to form communities with the people they share common interests with. The audience that people are trying to reach can be general or specific, all depending on what the writer is discussing in their online posts.

Audiences have to go and check into what the writers are writing to stay on top of the latest information. Writers have to find their niche and try hard to work their way into an already formed community. The target audience of the writer is able to respond to the writers' posts and can give feedback. The Internet allows these connections to be formed and fostered, hence giving room for the concept of "online audience". Internet creates a chance of being part of an audience and a creator at the same time.

\section{Theoretical Framework}

This study used the Discourse Analysis theory as its theoretical framework. A discourse is understood as the fixation of meaning within a particular domain. A discourse is established as a totality in which each concept is fixed as a moment through its relations to other signs. The theory was constructed by Ernesto Laclau and Chantal Mouffe in 1985. Laclau and Mouffe constructed their theory by combining and modifying two major theoretical traditions, Marxism and structuralism. Marxism provides a starting point for thinking about the social, and structuralism provides a theory of meaning.

The overall idea of discourse theory is that social phenomena are never finished or total. Meaning can never be ultimately fixed and this opens up the way for constant social struggles about definitions of society and identity, with resulting social effects. The creation of meaning as a social process is about the fixation of meaning. We constantly strive to fix the meaning of concept by placing them in particular relations to other actions.

According to Stubbs [17] discourse analysis is defined as a linguistic theory which is concerned with language use beyond the boundaries of a sentence/utterance with the interrelationships between language and society and the interactive or dialogic properties of everyday communication.

The term discourse analysis according to Slembrouck is very complex and ambiguous. It is used in this study as theory to lay a philosophical background to the analysis of online audience comments on media news sites. This is because the theory is connected with intensive look at speech or written discourse. However, it refers to attempts to study the organisation of language beyond the sentence or above the clause, and therefore to study larger linguistic units, such as conversational exchanges or written texts. It follows that discourse analysis is also concerned with language use in social contexts, and in particular with interaction or dialogue between speakers.

Discourse analysis does not presuppose a bias towards the study of either spoken or written language. In fact, the monolithic character of the categories of speech and writing is increasingly being challenged, especially as the gape of analysts' turns to multi-media texts and practices on the Internet.

Moreover, discourse analysis foregrounds language use as social action, language use as situated performance, language use as tied to social relations and identities, power, inequality and social struggle, language use as essentially a matter of practices rather than just structures. The reason for selection of this theory is that it has concern with the study of written and spoken text. It is in line with this study that seeks to analyse online audience comment on online news sites. The application of discourse analysis theory as philosophical background becomes imperative because it has assumptions that best stand for the analysis of written or spoken text. Bernárdez outlined the basic tenets of discourse analysis, which are summarized as follows:

Language only exists in use and communication. It always fulfills certain functions in human interaction.

Language use is necessarily social.

Language is not autonomous. It shares some characteristics with other social and cognitive phenomena.

The description of language must account for the real facts of language. It should not postulate hidden entities only motivated by the needs of the formal system utilized.

Linguistic structures should be closely linked to the conditions of language use.

Language is natural and necessarily vague and inaccurate; therefore any prediction can only be probabilistic.

Discourse analysts investigate the use of language in context, thus they are interested in what speakers/writers do, and not so much in the formal relationships among sentences or propositions. Discourse analysis, then, has a social dimension, and for many analysts it is a method for studying how language "gets recruited 'on site' to enact specific social activities and social identities” (Gee 1999: 1). Discourse Analysts explore matters such as: turn-taking in telephone conversations, the language of humour, power relationships in doctor/patient interviews, dialogue in chat rooms, the discourse of the archives, records or files of psychoanalysts, the scripts of a given television program, the discourse of politicians, the characteristics of persuasive discourse, the structure of narrative, the discourse of E-mail messages, audience comments on news sites among other.

\section{Methodology}

A review of related study identified that Critical Discourse Analysis (CDA) and Discursive Psychology Approaches as appropriate method for the study. Critical Discourse Analysis (CDA) Discursive Psychology Approaches are used to address research questions of this study. Critical Discourse Analysis stems from a critical theory of language which sees the use of language as a form of social practice. All social practice are tied to specific historical contexts and are the means by which existing social relations are reproduced or contested and 
different interests are served [18]. Critical discourse analysis subsumes a variety of approaches towards the social analysis of discourse as cited [18].

The Fairclough's model for Critical Discourse Analysis consists of three inter-related processes of analysis tied to three inter-related dimensions of discourse. These three dimensions are:

The object of analysis (including verbal, visual or verbal and visual texts). The object of analysis in this study is the online which is categorised under visual texts.

The processes by means of which the object is produced and received (writing/speaking/designing and reading/listening/viewing) by human subjects. The means by which the object of analysis was produced is classified under writing but within the context of the study an online writing.

The socio-historical conditions which govern these processes. The initial way of writing was hand and typewriting but with the emergence of ICTs it has alter the process as it bring along digital typing through computers, mobile phones among others.

According to Fairclough each of these dimensions requires a different kind of analysis:

Text analysis (description),

Processing analysis (interpretation),

Social analysis (explanation).

The useful thing about this approach is that it enables the researcher to focus on the signifiers that make up the text, the specific linguistic selections, their sequencing, and their layouts and so on. However, it also requires researcher to recognise that the historical determination of these selections and to understand that these choices are tied to the conditions of possibility of that utterance. This approach gives multiple analytic entries, because, It does not matter which kind of analysis one begins with, as long as in the end they are all included and are shown to be mutually explanatory. In this study the three-part analytic model for working with a text on the news sites will be applied.

According to Jorgensen and Phillips [19], Discursive Psychology centres on language use in everyday text and talk and is a dynamic form of social practice, which constructs the social world, individual selves and identity. Discursive psychology deploys many of the same methods as other qualitative approaches but discursive psychology differs from other qualitative approaches in how meanings are produced within the discourses that people draw on as resources in order to talk about aspects of the world [19]. Discursive Psychology deploys many of the same methods (coding, transcription, interview etc.) as other qualitative approaches.

At this point, because the researcher is interested in studying audience comments on online media news sites over the subsidy removal in Nigeria, then the data of the researcher are audience comments posted under the news items on the sites of Sahara Reporters and Premium Times. These data are primary data because they are collected and compiled by the researcher. So, the researcher collects all the comments of audience on the identified stories on the two news sites.

Because of the dynamic nature of online news sites there is no standing number of the sites, but as at the time of this study there are more than 200 online news sites in Nigeria according to "Naija Dailies" an online platform which arrange news sites for readers [20]. These serve as the population of the study. The researcher purposively selected comments on the subject that are constituted around the issue under study and filter those that are not related. Content categories of this study include: positive and negative comments, tone of the comments (fragmented based on political, regional and ethnic affiliation) and overriding position of the audience comments (Table 1).

To effectively analyse the audience comments under the news item posted on the two selected online-based media themes were drawn based on the objective of the study. Comments posted by the audience on the sites of the news media were read and reread in order to identify and place them in the relevant themes. The themes drawn are: comments that are positive and negative, comments considered fragmented based on political, regional and ethnic affiliation. To identify the key messages in comments, which included offensive speech, attack and defence, the study conducted an analysis of macro propositions. According to Van Dijk cited by Wilson and Gapsiso [6], macro propositions analysis is based on an identification of the most relevant collection of information in a text, derived from the local meanings of words and sentences by macro rules, such as deletion, generalisation and construction. In this case, the study looked at the comments in which audience acclaim, attack or defends the issue under study; comments that are negative or positive, titled toward political, regional and ethnic affiliation and overriding position of the online audience comments on subsidy removal in Nigeria in 2016. The findings were quantitatively and qualitatively presented.

The study used Coding Sheet as instrument for data collection. Coding data, it means assigning attributes to specific units of analysis, such as paragraphs, sentences, or individual words. In an online post users usually tag online information like pictures, links, or articles. Coding is simply an academic version of this tagging process.

The study adopted quantitative method for data presentation "nominal level data measurement". Quantitative data analysis is helpful in evaluation because it provides quantifiable and easy to understand results [21]. The study used tabular presentation using simple percentage analysis technique to presents its findings, In the table, the nature of the post comments would be arranged along the vertical line, whereas on the horizontal line the units of analysis-news stories and audience opinion comments. To enhance the quality of the presentation screen shots of the comment is used to accompany the tabular presentation.

\begin{tabular}{|l|l|}
\hline Content Categories & Description \\
\hline Positive Comments & Comments that are favourable to the subsidy removal issue, personalities involved etc \\
\hline Negative Comments & $\begin{array}{l}\text { Comments that are unfavourable to the subsidy removal issue, personalities involved or hostile to the news media that reported the issue, } \\
\text { other audience etc }\end{array}$ \\
\hline Political comments & Comments that chanted a particular political ideology, political personalities, slogan etc \\
\hline Regional comments & Comments that chanted regional sentiment, believe, groups, personalities etc \\
\hline Ethnic comments & Comments that chanted particular ethnic group, personalities of the group, believe of the group, tradition of the group etc \\
\hline
\end{tabular}

Table 1: Content categories and Description. 


\section{Data presentation and analysis}

The data collected were presented and analysed based on research questions of the study. A total of 215 comments were identified under two selected posts from the two media (Sahara Reporters and Premium Times).

RQ1: Are there positive online audience comments on the 2016 subsidy removal issue in Nigeria?

From the 215 comments analysed, the above table indicate that there are 65 positive comments. The positive comments are classified into two; positive toward the subsidy removal issue and positive toward personalities (President, Minister etc) involved in the subsidy removal issue. There are $47(72.3 \%)$ positive comments toward the subsidy removal issue which indicate an acceptance of the policy by some audience (Table 2). The examples of these are:

"Subsidy removal has always gained my support any day any time...."

"........Almost all Nigerians has been urging the government to deregulate so that they can have fuel to buy. The burden was too heavy financially for the government to bear, this should be a welcome decision and relief to everyone. As this is what the people, lets hope it will eventually lead to competition and fall in price"

"I am willing to accept the new price if the federal government present a tangible plan and a timetable for the restoration of the local refineries to 100 percent capacity. We need a clear and detailed plan. Solve this problem once and for all. I understand the government can't even pay salaries and want to spend massively on infrastructure that is why they don't want to pay fuel subsidy. But we need a long term solution to our problems. The reality is if the local refineries work, there will be no need for forex differentials or for import of oil. There will be no need for price increase of PMS. President Buhari please give us a final solution, enough is enough"

"...removal of subsidy would curtail corruption so it had nothing to do with being trustworthy or corrupt..........Removal of subsidy allows competition and the market to dictate the price"

"Deregulation had its merits then no doubt but the problem was the proponent of deregulation. When a woman says NO for the first time, she does not necessarily mean NO but saying tell me more about yourself, prove to me that you love me, I want to know about you... GEJ and his band failed in providing the right answers and so the people saw that he cannot be trusted hence the protests and with the subsidy scam + all the revelations of today, Nigerians were right in saying NO to him 2012"
RQ2: Are there negative online audience comments on the 2016 subsidy removal issue in Nigeria?

The above table indicates that apart from the positive comments, there are also audience comments that have negative coloration. The analysis found 103 negative comments, 31 (30\%) comments are unfavourable to the subsidy removal issue, 49 (47.5\%) comments are unfavourable to personalities and government involved (Table 3). There are $7(6.7 \%)$ comments that are hostile the media that reported the issue whereas $16(15.5 \%)$ comments are unfavorable toward other audience or other comments. Examples of some comments that are unfavourable to the subsidy removal issue include:

"I don't know how this makes common sense for a marketer to be subject to the USD parallel market and yet have a cap on its sale price. Somebody please explain this to me. NNPC will import with FOREX at CBN rate which is almost $50 \%$ of what obtains in the parallel market, and other marketers will at black market rate? NNPC stations will sell at not more than $=\mathrm{N}=145$ and other marketers too? If this is the summary of the new policy, then I am in shock. I pray I am over reacting! In all of this, the common man continues to suffer"

"I don't have problem of whatever they call it. My problem is the hike of the price of the petrol to N145 per litre which is going to affect negatively, the lives of over 170 million people"

"Rejected. It costs Nigeria less than $\$ 10$ per barrel to produce Crude Oil. At N145 per liter fuel will be selling at above $\$ 140$ per barrel. Deregulation means PPPRA must be scrapped and prices allowed to determine their level. Crude oil access must be open to any buyer at bid price just like Forex. Anyone can import product means DPR only monitors quality and statistics. Deregulation by fixing price is nonsense"

"Now someone has to explain the new job of the PPPRA. No more price control"

"Why do we support this deregulation without presenting roadmap Infact Nigerians were not informed of happening only that MrKachukwu came onboard and be informing us what has happened, anyway there should be no deregulation until when I know the days or months even years that good road networks will pass across Nigeria, when salary increment will be approved, when power will be without interruption, when railway network will be installed and effective. When all these questions are answered then there should be deregulation, this kind of hiruhuru deregulation should not be accepted at all, this is not the type of change we are expecting, a change that will cater for citizenry is what we are clamouring for"

\begin{tabular}{|l|l|l|c|c|}
\hline S/N & Directions & Description & Number of Comments & Percentage \\
\hline 1 & Positive toward the subsidy removal issue & Comments that are favourable to the issue & 77 \\
\hline 2 & $\begin{array}{l}\text { Positive Toward Personalities (President, } \\
\text { Ministers etc) involved in subsidy removal issue }\end{array}$ & $\begin{array}{l}\text { Comments that are favourable to personalities or } \\
\text { government involved }\end{array}$ & $\begin{array}{l}72.3 \% \\
27.6 \%\end{array}$ \\
\hline Total & & & 18 \\
\hline
\end{tabular}

Table 2: Category of Positive Comments.

\begin{tabular}{|c|c|c|c|}
\hline S/No. & Directions & Number of Comments \\
\hline 1 & Negative toward the issue & 31 \\
\hline 2 & Negative toward Personalities involved & 49 \\
\hline 3 & Negative toward the media & 7 & $7.5 \%$ \\
\hline 4 & Negative toward the audience & 16 & $7.7 \%$ \\
\hline Total & & $15.5 \%$ & 103 \\
\hline
\end{tabular}

Table 3: Category of Negative Comments. 
"This is delusion. The prices once they go up will never come down again. The government is simply trying to sustain its budget on the back of its citizens. This is a road we should avoid. There are other alternatives. He is simply stifling the economy. You will see before the end of the year"

The analysis found that, out of 103 negative comments identified $49(47.5 \%)$ comments are unfavourable or attacked the personalities, parties and the government involved. Examples of such comments are:

"Increasing economic hardship is a sure bet to bring down any government. I thought all politicians know this, perhaps not Buhari...."

"The Jonathan administration is gone. Nigerians voted for "Change" and "Sai Baba." By various missteps, the Buhari administration has made many things worse...........Buhari put a lawyer in charge of oil exploration and production; a lawyer in charge of power, works and housing; a lawyer in charge of the budget; etc."

"This is very selfish and it shows Buhari is nit in government. He should better spend more time at home. No one is coordinating the economy right now"

Some of the negative or unfavourable comments were directed toward the media organization for being biased, overlooking some issues and over blotting other issues. Some of the comments discredited the media and used abusive words to accuse their pattern of reportage as suitors of one party, personality and region. Some of such comments include:

"Sahara reporters are a bunch of hypocrites. There are no fire and brim stones now that their pay masters are in government. Money lasts only temporarily but truth, justice and fairness lives forever"

"Sahara has failed to use a captivating heading line for this news. Fuel, electricity ....everything on increase and yet they are scarce. Sahara we are expecting a hash tag in this"

"PPPRA will be announcing a new price band... and the new price will not be above N145 per liter" yet your headline screams "Nigeria Deregulates'...?"

RQ3: What are the tones (Political, regional and ethnic) of the comments on the subsidy removal issue in 2016 segmented?

The analysis found that some of the comments were fragmented toward political affiliations (parties, personalities and ideology), regional and ethnic sentiments. Some of the tones are titled in support of the personalities involved in the subsidy removal issue with the perception that major government actors belong to particular region, ethnic or political organization (Table 4).

The analysis found that there are audience comments that have political composition. The analysis found 25 comments with political compositions, 5 (20\%) comments chanted or sang either for or against the political slogans of party involved in the subsidy removal issue, 9 (36\%) comments chanted political personalities either in government or opposition. Majority of the political comments chanted political ideologies. Examples of some comments that have political colorations include:

\begin{tabular}{|l|l|c|c|}
\hline S/No. & Tones & Number of Comments & Percentage \\
\hline 1 & Political Comments & 25 & $11.6 \%$ \\
\hline 2 & Regional & 19 & $8.8 \%$ \\
\hline 3 & Ethnic & 3 & $1.3 \%$ \\
\hline Total & & 47 & $100 \%$ \\
\hline
\end{tabular}

Table 4: Tones of Comments.
"APC CHANGE! SaiBaBa... Jonathan must be choking with laughter... I cannot forget how a senior APC chieftain few weeks before the 2015 Presidential Elections analysed why fuel (PMS) should sell below 86-naira... Yes, even President Buhari said that the fuel subsidy was a scam and a ploy to rip-off Nigerians"

"And under PDP, petrol is cheap and water is plentiful and cheap!"

“APC always try to do the right thing, after they've tried everything else...”

"D political unwillingness of Jonathan was a major contributor on $\mathrm{y}$ he was unable to remove $\mathrm{d}$ subsidy..APC CHANGE"

"SAI BABA, Sai Buhari"

"We can see clearly now. Nigerians has been scammed by the promise of CHANGE. In fact, GEJ is an angle to compare with this man we call our president"

Tones of some comments were tilted towards regional sentiments and chanted personalities from various regions of the country. Some of the comments were abusive and designed to downgrade people, personalities and image of the region. Some of them are:

\section{"SaiTompolo!"}

"They do not need to protest because they know the money to bensure saved from the removal of subsidy will not be looted by one useless Otuoke man and his illiterate wife along with their comrades in stealing and then turn around to say stealing of public funds is not corruption"

"Yes I remember...That bloody northern liar's name is Gen. Buhari under whom massive looting of the PTF took place, but whom APC's hopeless barracudas have chosen to crown patron saint!!!!!"

"Oya o, idey wait for all biafrans to begin abuse baba!"

RQ4: What is the overriding acceptance or rejection of the 2016 subsidy removal in Nigeria in the online audience comments?

The overriding position was negative comments or comments that are unfavourable to the issue and personalities involved. Out of the 215 comments from the two selected media analysed, there are 103 negative comments out of which 49 were directed toward the personalities or parties involved which include the President, Minister, their political parties among other personalities, while 31 were directed to the subsidy removal issue. This indicates a plausible argument that the majority of the audience rejected the 2016 subsidy removal in Nigeria. Most of them showed their disagreement through direct attack on the personalities involved in the issue. The personalities involved in the issue include the President of the Federal Republic of Nigeria who is also the Minister of Petroleum Resources, Minister of state for Petroleum Resources, Minister of Information and Culture. Their names were mentioned in various comments made by the audience.

On the other hand the media that reported the issue also suffered some negative comments from the audience. Abusive words were used to refer the media as biased and suitors of a particular political group or region. This indicated the fact that the audience rejection has reached an extent of attaching the issue to the biasness of the media. The analysis also identified some negative comments toward other audience who have commented on the issue. As a response to audience who commented in support of the issue, there were many abusive comments made by high number of the audience who have rejected the issue. These categories constituted the highest number of comments 
and indicate higher number of audience that rejected the 2016 subsidy removal in Nigeria.

\section{Discussion of Findings}

The recent advancement and involvement of audience participation or engagement in news process was greatly enhanced by the advent of Information and Communication Technology (ICT) which internet cannot be neglected. In contrast to days before the change in information and communication pattern in the society, the participation of audience in media is usually limited. Audiences only participate in media through opinions, petitions and letters to the editors. These sometimes attract the attention of the media for future considerations. Some of the conventional audiences' reactions though delayed but most often lead to instant correction by the media. This indicates the delayed model of communication between media and its audience. It has also made audience to be passive with regard to media content.

This was the situation until the emergence of ICTs that have virtually changed every facet of life which media practice is not an exception. It has altered the process of communicating with media audience. The Information Age exemplifies the mainstreaming of technology into every business of life. The study found that the technology is used by media to engage and measure their audience readership, traffic on their sites through web techniques. The provision for audience to comment on issues is one of the techniques that have open up a great opportunity for audience to participate and make their contribution in the discourse of local, state and national affairs in the media.

The discourse analysis theory proposed an extensive study of either written or spoken statement in order to derive meaning out of it. The meaning is derived based on its composition through the use of word choice, sentence construction, use of terms etc. this study justify that a critical look at text give room for identifying meaning attached to words and statements. The use of discursive psychology helped in determining and classifying the comments according to the psychological construct contain in the comments. The anonymity of the online platform has given the audience sense of rejecting or accepting issues without contextual hindrance. Based on the analysis, it is apparent that media organizations now operate online sites for reaching more audience. Through these sites audience are provided with opportunity to express themselves through comments, likes, tags among others. This has been demonstrated from the comments made by audience about the 2016 subsidy removal issue in Nigeria. This correlate with the argument of Wilson and Gapsiso [6] that during days of delayed audience response comments, articles, opinion from audience that do not meet the interest of media owners, relations and friend of media owners are often left unpublished, whether the opinion is in the interest of the nation or not. But with these developments in the interaction between media and audience and the fact that anonymity is key in the relationship, audience now have the opportunity of posting comments under news items with little or no hindrance as was the case with 2016 Subsidy Removal issue in Nigeria. This implies that the online platform has enable Nigerians to express their views on local and national issues devoid of hindrance by the media.

Such opportunity has also provided the audience with right to react to government policies. The sense of rejection has been demonstrated by the audience on the sites of the two selected media on subsidy removal issue. Consequently, there is identified abuse of such rights by the audience in the participatory online journalism by the use offensive speech, words and terms against groups, personalities and organizations. This instance draw a parallel with tones and overriding comments of online audience on subsidy removal issue in Nigeria in 2016.

However, it is the heterogeneity of audience that leads to the variations and tones of comments about subsidy removal issues in Nigeria. This occurs on the background that everybody is entitled to use the internet, visit news sites and make comments sometimes without clear identification of the audience. The ability of being anonymous on the medium made them to engage in uncivil comments.

The main finding from the critical discourse analysis conducted found that online audiences have commented on the subsidy removal issue in Nigeria in 2016. The first research question asked thus; are there positive online audience comments on the subsidy removal issue in Nigeria in 2016?

The analysis found that there are online audiences that made positive comments on the issue. The positive comments are those comments made in support of the issue. There are positive comments that were directed toward the subsidy removal issue while others were positive toward the personalities (President, Ministers and other political leaders) involved. These findings correlate with scholars who argue that most people online are far more likely to be nice than resort to rude, hostile, and uncivil communicative behavior. This finding provides answer to the research question which seeks to find out whether there are positive comments made by the audience on the 2016 subsidy removal in Nigeria.

The second research question reads; are there negative online audience comments on the subsidy removal issue in Nigeria in 2016? The study found that exorbitant numbers of comments were negative. The negative comments implied comments that are unfavourable to subsidy removal issue. The analysis found that some negative comments attacked the subsidy removal issue, attack on personalities involved in the new policy, parties or political affiliation of the government involved in the issue. There were comments that engaged in exchange of abusive words among the audience over the subsidy removal issue. There were also attacks on the media that reported the issue itself. These findings correlate with argument of Eveland and Shah that, intense comments debates on media bias and people's own perception of biases have lead to unhealthy amounts of skepticism in the mainstream media. Yet the nature of that apparent bias in the news varies.

The study found that some comments were tilted toward political, ethnic and regional sentiments. This answered the third research question which read; what are the tones of the comments on the subsidy removal issue in 2016 segmented? There are identified comments that have tones of ethnic affiliation, regional sentiment and political inclination. There are political comments that chanted particular political personality, party slogan and ideology, the number of ethnic comments is negligible compared to other tones because there are only 3 comments which constituted only (1.3\%) of the comments analysed. There are also comments with tones of regional sentiment. This finding concur with Rowe (2013) who says some people explicitly seek out different opinions, while others are seeking content that matches their own views. Indeed, as online discussion allows participants to remain relatively anonymous, and by extension, unaccountable for their behaviour, citizens often engage in angry, hostile, and derogatory discussion, taking the opportunity to attack the beliefs and values of others without fear of retribution.

\section{Conclusion}

The emergence of online media is a great development in 
Citation: Umar MA (2018) Analysis of Online Audience Comment on 2016 Subsidy Removal Issue in Nigeria: A Case Study of Premium Times and Sahara Reporters. J Mass Communicat Journalism 8: 363. doi: 10.4172/2165-7912.1000363

enhancing media discourse. Online media is an essential tool that gives more opportunities for audience to participate with immediacy in the discussion of local, national and international affairs. As exhibited in the findings of this study, the opportunity has been exploited by the audience as many of those who comment expressed their dissatisfaction with the subsidy removal. The way other comments were composed along ethnic, political regional shapes as well as posting negative and injurious comments, has the capabilities of relegating the platform into combat zone where audience unhealthy conversation.

To this end, it is the conclusion of this study that the online news service or platform arrived with positivity and negativities but the audience explored more of the negativities than the positivity; this is seen in their unhealthy conversation and comments towards the media organization. It is also my argument that the exploration of the negativity is inextricably linked to the anonymity provided by the platforms. The online comments have also brought about balance in tone of public opinion towards government policies, this boils down to the fact media advancement overtime gave audience degree of power to hold and express their perspectives on issues. The result of this analysis gave a picture of how less Nigerians comment with ethnic composition on issues that affect virtually everybody in the country, distinct from what is invariably obtainable on other issues related to ethnic practices, ethnic leaders, ethnic values and culture generally.

\section{Recommendations}

However, increasing abuse, glorifying violence and tension has revealed the disadvantaged nature of online media. The following recommendations are hereby made:

There should be moderation and vetting of online comments by the media in cases of clear misuse of the platform. The moderation is required to enable the platform serve its intended purpose as discussion platform and provide opportunity for audience to air their view.

There is need for online audience to engage in healthy conversation on the online platform while expressing their view on local, regional and national issues in order to enhance the collection of audience opinion about policy issues. This will improve and encourage some level of decency in the discourse of national issues.

There is need for online media to establish more procedure for identifying the identity of online audience before approving their comments. This can be done through connection with social media pages like Facebook, Twitter etc securing sign up and registration of individuals on the platform that would eradicate deep anonymity.

\section{References}

1. Hermida A (2011) Mechanisms of participation: How audience options shape the conversation. Participatory Journalism: Guarding Open Gates at Online Newspapers. Malden: Wiley Blackwell.

2. Gurevitch M, Coleman S, Blumler JG (2009) Political Communication: old and new media relationships. Annals of the American Academy of Political and Social Science 625: 164-181.

3. Reich Z (2011) User comments: The transformation of participatory space Participatory journalism: Guarding open gates at online newspapers Malden, MA: Wiley-Blackwell.

4. Weber P (2014) Discussions in the comments section: factors influencing participation and interactivity in online newspapers' reader comments. New Media \& Society 16: 941-957.

5. Henrich N, Holmes B (2013) Web news readers' comments: towards developing a methodology for using on-line comments in social inquiry. Journal of Media and Communication Studies 5: 1-4.

6. Wilson J, Gapsiso N (2014) Social media and the freedom of expression in Nigeria: posting the mind of a nation. The International Journal on Internet Trolling and Online Participation 1.

7. Olatunji S (2012) Fuel subsidy: Nigerians descend on Jonathan's supporters.

8. Marisa TS (2015) what do users have to say about online news comments? Readers' accounts and expectations of public debate and online moderation: a case study. Journal of Audiences and Reception Studies 12: 32-44.

9. Jimoh OO, Omoniyi AA, Agboola LO, Abdulmutallib AA (2014) Press reportage of 2012 fuel subsidy removal crisis in Nigeria. Developing Country Studies 41-5.

10. Sandvik K (2011) Fire grader afbrugerindflydelse (Four degrees of use influence). In Harvard S. (ed.), Medie DK. Copenhagen: L\&R Uddannelse.

11. Wahl-Jorgensen K, Williams A, Wardle C (2010) Audience views on usergenerated content: Exploring the value of news from the bottom up, Northern Lights. Film and Media Studies Yearbook 8: 177-194.

12. Damásio MJ, Poupa C (2008) Understanding online audiences: new research approaches. Media Psychology Review 1.

13. Shirky C (2008) Here Comes Everybody. Penguin Group

14. Vujnovic M (2011) Participatory journalism in the marketplace: Economic motivations behind the practices. Malden, MA: Wiley-Blackwell, Oxford, UK.

15. Meyer H, Michael C (2014) In moderation: Examining how journalists' attitudes towards online comments affect the creation of community. Journalism Practice 8: 213-228.

16. Rosen J (2006) The People Formerly Known as the Audience.

17. Stubbs M (1983) Discourse Analysis: The Sociolinguistic Analysis of Natural Language. Oxford: Basil Blackwell.

18. Fairclough N (1995) Critical Discourse Analysis: The Critical Study of Language. Harlow: Pearson Education Limited.

19. Jorgensen M, Phillips L (2002) Discourse analysis as theory and method. London; Sage Publications.

20. Naija Dailies (2016) Top 200 Nigerian online newspapers and blogs.

21. Pell Institute (2016) Analyze quantitative data 